INTERNATIONAL JOURNAL OF MULTIDisciplinARY RESEARCH AND ANALYSis

ISSN(print): 2643-9840, ISSN(online): 2643-9875

Volume 04 Issue 09 September 2021

DOI: 10.47191/ijmra/v4-i9-11, Impact Factor: 6.072

Page No.- $1268-1275$

\title{
Prevalence and Outcome of Obstructed Labour at a Tertiary Institution
}

\author{
Elizabeth Nionzima ${ }^{1}$, Wilfred Inzama ${ }^{2}$, Charles Otim Tom ${ }^{3}$ \\ ${ }^{1}$ Mulago Specialized Women and Neonatal Hospital, P. O Box 22081, Kampala, Uganda \\ ${ }^{2}$ Lira University, P.O. Box 1035, Lira \\ ${ }^{3}$ Lira University, P.O Box 1035 Lira
}

\begin{abstract}
Obstructed labour is a common preventable causes of both maternal and perinatal morbidity and mortality in developing countries affecting 3-6\% labouring women globally and accounts for an estimated $8 \%$ of maternal deaths in SubSaharan Africa and South Asia.
\end{abstract}

Objective: To determine the prevalence and outcome of obstructed labour in the Gynaecology and Obstetrics Department at a tertiary hospital in Northern Uganda.

Method: This was a retrospective chart review of pregnant women admitted in labour and delivered by caesarean section from $1^{\text {st }}$ January 2016 to 31st December 2017 at a Lira Regional Referral Hospital, a tertiary institution in Lango Sub region. Data was analysed using Statistical Package for Social Sciences version 16.0.

Results: A total of 808 medical charts of mothers with obstructed labour were retrieved, evaluated and included in this review out of 12,189 deliveries during the study period, giving a prevalence of $6.6 \%$. Majority (77\%; 622/808) mothers admitted with diagnosis of obstructed were referred in from peripheral facilities. Over half $(53.4 \%)$ of the women were in the age group of 20 to 29 years. Over 53\%, were prime gravidae and were twice more likely to undergo $\mathrm{C} / \mathrm{S}$ due to obstructed labour than multigravidas (OR 1.8; $95 \% \mathrm{Cl}$ 1.5-2.2). Only 49.2\% had documented cause of obstructed labour, with Cephalo-pelvic disproportion being most common (17.5\%), malposition/mal-presentation (14.6\%), and macrosomia (3.6\%). Partograph was used in only $46.6 \%$ (374) women who had obstructed labour. The commonest maternal complication observed were Sepsis (11\%), PPH (5.2\%), uterine rupture (4\%) and burst abdomen (3\%) which led to prolonged hospital stay and loss of fertility to some.

Mode of delivery in the 808 reviewed charts was caesarean section, $90.3 \%$ of babies were born alive, while $8.5 \%$ (69) were born dead, (1.2\%) had early neonatal, and $40.2 \%$ were referred Paediatric Neonatal Intensive Care Unit (NICU) because of low APGAR score.

Conclusion: The prevalence of obstructed labour among women delivered by Caesarean section was high compared to the global average. Majority of the women were referrals from the peripheral health centres and associated with life threatening complications and even death. Young age and prime gravida is associated with obstructed labour and high caesarean section rates. The obstruction in multigravida could be due to secondary cephalo-pelvic disproportion as majority of the babies were in normal range weight. Low use of Partograph to monitor labour was evident among women who had obstructed.

KEYWORDS: Obstructed labour, Caesarean section, Maternal and Perinatal outcome.

\section{INTRODUCTION}

Obstructed labour is still a common preventable causes of maternal and perinatal morbidity and mortality [1, 2, 3]. It affects 3 $6 \%$ of labouring women globally per year [4]. Obstructed labour and its complications in Sub-Saharan Africa, and South Asia accounts for an estimated $8 \%$ of all maternal deaths. Most of the deaths from obstructed labour are associated with haemorrhage, infections, metabolic and electrolyte derangements [5]. In Uganda, obstructed labour accounted for 26\% of maternal deaths in a study conducted in Gulu, Northern Uganda [6]. In Uganda, low uptake of antenatal care services, poor quality intra-partum care, inadequate knowledge and skills are some of the predisposing factors to obstructed labour [7]. The common causes of obstructed labour are cephalo-pelvic disproportion (CPD), fetal malposition and mal-presentation [8, 9, 10, 


\section{"Prevalence and Outcome of Obstructed Labour at a Tertiary Institution."}

1]. In few cases soft tissue obstruction in maternal passage like pelvic tumours or congenital malformation of fetus like hydrocephalus can also lead to obstructed labour [11]. Apart from maternal death, it is associated with high perinatal death, a number of debilitating and distressing maternal morbidities, which include genital sepsis, uterine rupture, vesico-vaginal fistula, gynaetresia, amenorrhea, impaired fertility [1].

In the case of this study area, there was no data even though the problem is believed to be common. Therefore, this study was of paramount importance to fill the gap regarding the inadequacy of information about the problem, identifying specific cause of obstructed labour, scaling up evidence based intervention and measuring the progress in improving maternal child health. It also helps the policy makers to plan and implement evidence-based action to reduce the problem. Therefore, this study was planned to assess prevalence of obstructed labour at the tertiary hospital. The data obtained from this study will also assist policymakers, planners, and other collaborators in the health sector to formulate appropriate strategies and interventions to tackle the problem.

\section{MATERIALS AND METHODS}

This was a retrospective chart review of women admitted on the Maternity Ward, a diagnosis of obstructed labour was made and subsequently delivered by caesarean section between January 2016 and December 2017 at Lira Regional Referral Hospital. Lira Regional Referral Hospital is a tertiary health care facility and provides specialist health care services to the eight districts of Lango Sub-region. It has an annual delivery of over 60,000. Data was analysed using Statistical Package for Social Sciences version 16.0 .

All clinical charts of women with gestational age of 28 weeks and above or birth weight of more than $500 \mathrm{gm}$ with diagnosis of obstructed labour and were delivered by caesarean were reviewed. Two research assistants (midwives) were trained on the purpose of the study, objectives, procedures and the data collection tools before the commencement of the study by the Principal investigator. Questionnaires were pre-tested and adjustments accordingly. Patient records, operation theatre notes; and theatre and labour ward registers were reviewed retrospectively to gather information about the obstructed labour. All the relevant information such as age, parity, previous obstetric history, causes, and complications, maternal and neonatal outcome were collected. Gestational age was calculated on earlier dating with LMP or ultrasound where available

The data was analysed with Statistical Package for Social Sciences (SPSS version 16.0) to describe frequencies of variables, their percentages were calculated and associations were assessed. Mean and standard deviations was computed for quantitative variable like frequency, age, gestational age, parity and perinatal outcome. Data was displayed in tables and figures. Significance level was considered at $P$ value $<0.05$ at $95 \%$ confident interval.

\section{A. Ethical Consideration:}

Approval was obtained from, Research Ethical Committee of Lira Regional Referral Hospital. Names of the participants were not used in the study and confidentiality of the patient information was maintained.

\section{B. Inclusion criteria:}

All deliveries conducted in the obstetrics and gynaecology department with Gestational age from 28 weeks and above or birth weight greater than $500 \mathrm{gm}$. and delivered at LRRH by caesarean section were included.

\section{Exclusion criteria:}

Women whose gestational age was less than 28 weeks, women admitted postpartum and those who were discharged before delivery or delivered by spontaneous vertex delivery.

\section{Definitions}

For the purpose of this study the following definitions were applicable.

Obstructed labour: Failure of descent of the fetal presenting part for mechanical reasons in spite of adequate uterine contractions and not managed timely [12].

Diagnosis of obstructed labour: This was made from history and clinical examination; by the presence of one major criterion and one or more of the minor criteria. Major criteria: presence of bandl's ring, cervical oedema, moulding grade III. Minor criteria; fetal and maternal distress and dehydration, prolonged labour and abnormal vaginal discharge.

Neglected obstructed labour: Labour with no advance of the presenting part of the fetus despite adequate uterine contractions if left untreated for thirty or more minutes from the time of diagnosis [12]. 


\section{"Prevalence and Outcome of Obstructed Labour at a Tertiary Institution."}

\section{RESULTS}

A. Prevalence And Associated Risk Factors Of Obstructed Labour

The total number of deliveries from January 1st 2016 to December 31st 2017, was 12,189 of which 2600 were by caesarean section and 808 cases were diagnosed to have obstructed labour. The percentage incidence of obstructed labour was $6.6 \%$ of the total deliveries and $31.1 \%$ of the total caesarean section. This was comparable to a study in Ethiopia [13] but lower than that reported in western Uganda $[7,14]$ and in other studies $[11,15,16]$ in some African countries. This may be due to the fact that it is a referral facility and geographically accessible which increases referral cases and the finding also agree with this assumption because $53.4 \%$ of cases of obstructed labour were referrals in. The Caesarean section rate was $21.99 \%$ of total deliveries; a rate high than the expected $[17,18]$.

Table I: Prevalence of obstructed labour

\begin{tabular}{|l|l|l|l|}
\hline & 2016 & 2017 & Total \\
\hline Total number of deliveries & 7288 & 4901 & 12189 \\
\hline Total number of vaginal deliveries & 5724 & 3865 & 9589 \\
\hline Total number of caesarean deliveries & 1564 & 1036 & 2600 \\
& $(22.4 \%)$ & $(21.4 \%)$ & $(22.0 \%)$ \\
\hline Total number of Obstructed labour & 495 & 313 & 808 \\
& $(31.9 \%)$ & $(30.2 \%)$ & $(31.1 \%)$ \\
\hline Prevalence of obstructed labour & $6.82 \%$ & $6.39 \%$ & $6.6 \%$ \\
\hline
\end{tabular}

Socio-demographic characteristics of the mothers with obstructed labour: Table II shows the socio-demographic characteristics of 2600 women, who underwent caesarean section during the study period. The mean age of study participants delivering at LRRH by caesarean section was 24.6 years with standard deviation of 5.9; and a the minimum and maximum of 13 and 49 years respectively as in other studies [10, 20]. More than half $(63 \%)$ of the study population were 24 years and below and teenage mothers contributed to $30.5 \%$ (Table II) of the obstructed labour.

The mean age of the mothers with obstructed labour was 23.65 years which was significantly lower than the mean age of 25 years for those without obstructed labour ( $t-5.461$; df 2598, p 0.000). Mothers aged $\leq 24$ years were twice more likely to undergo caesarean section due to obstructed labour than those aged $\geq 25$ years (OR $1.5 ; 95 \% \mathrm{Cl} 1.3-1.8$ ).

Table II: Socio-Demographic Characteristics/Associated factors

\begin{tabular}{|c|c|c|}
\hline Characteristic & $\begin{array}{l}\text { Total Number } \\
(\mathbf{n}, \%)\end{array}$ & $\begin{array}{l}\text { Obstructed labour } \\
\text { (no. \& \% of total) }\end{array}$ \\
\hline \multicolumn{3}{|l|}{$\begin{array}{l}\text { Age group of the } \\
\text { mother (Years) }\end{array}$} \\
\hline $13-19$ & $598(23.0)$ & $245(9.4)$ \\
\hline $20-29$ & $1467(56.4)$ & $430(16.5)$ \\
\hline $30-39$ & $496(19.1)$ & $124(4.8)$ \\
\hline$\geq 40$ & $39(1.5)$ & $09(0.3)$ \\
\hline Parity & $1117(43.0)$ & $428(16.6)$ \\
\hline $1-4$ & 1099 (42.3) & $277(10.7)$ \\
\hline $5-9$ & $380(14.6)$ & 101 (3.9) \\
\hline$\geq 10$ & $04(0.2)$ & $02(0.1)$ \\
\hline $\begin{array}{l}\text { Mothers Referred } \\
\text { in }\end{array}$ & $1172(45.1)$ & 432 (36.9) \\
\hline $\begin{array}{l}\text { Referral from } \\
\text { CEMONC Site }\end{array}$ & $534(20.5)$ & $190(35.6)$ \\
\hline $\begin{array}{l}\text { Partograph } \\
\text { plotted }\end{array}$ & $1008(38.8)$ & $375(37.2)$ \\
\hline $\begin{array}{l}\text { Repeat Caesar } \\
\text { section }\end{array}$ & $469(18.0)$ & 55 (11.7) \\
\hline
\end{tabular}




\section{"Prevalence and Outcome of Obstructed Labour at a Tertiary Institution."}

Obstructed labour and associated factors: A total of 1172 or $45.1 \%$ who had Caesarean section were referrals in to LRRH and $53.4 \%$ (431) of those referred in had obstructed labour and this constituted $28.5 \%$ of the total deliveries by Caesarean section. Mother referred in were 52.13 times more likely to have obstructed labour than those not referred in ( $P$ value 0.000$)$ and at an increased risk of 1.852 (95\% Cl: 1.565-2.191. Of the total mothers, $7.3 \%$ or 190 of who had Caesarean section due to obstructed labour were from other CEMONC sites within the region (Table II). More than 1/2 (429; 53.4\%) of the obstructed labour occurred within the facility (LRRH). This may reflect the quality of intrapartum care, but also that the institution is a training ground with students of different categories.

Obstructed labour was more prevalent in the teenage mothers, prime para and those referred to the facility (Table II). Teenage mothers with obstructed labour comprised of $30.5 \%$ of the total mothers with obstructed labour and had caesarean section and $9.4 \%$ of the total caesarean section deliveries which is higher than the global figures of 3-6\% [12, 20]. There was a 1.5 times increased risk of obstruction in prime gravid than in multigravida and the relationship was statistically significant ( $\mathrm{p} \leq 0.0001)$.

Less than half of mothers who had obstructed labour had a Partograph started to monitor labour (Table II). Mothers who were not monitored on a partograph were more likely to have obstructed labour than those monitored on the partograph (OR $1.6 ; 95 \% \mathrm{Cl} 1.4-1.9 ; \mathrm{p} 0.000$ ) showing that the partograph used appropriately reduces the occurrence of obstructed labour.

Obstructed labour was the main indication for Caesarean section accounting for 31.0\% (table III) of the total Caesarean section done. The 10 most indications for Caesarean section are shown in the table III and these accounted for $93.2 \%$ of the caesarean sections. The causes of obstructed labour are shown in table IV, were documented in only 397 (49.1\%) cases out of the 808 Caesarean section performed for obstructed labour. Among the mothers were the cause of obstructed labour were documented, 187 (23.1\%) were due to CPD, 161 (6.2\%) due to mal-presentation/malposition, 40 (5.0\%) due to big baby and 08 (1.0\%) due to cervical dystocia and fetal anomaly to $1(0.1 \%)$.

Table III: The Ten most common indication for caesarean section

\begin{tabular}{|l|l|l|}
\hline Indication & Number $\mathbf{( n = 2 6 0 0 )}$ & Percentage \\
\hline Obstructed labour & 808 & 31.1 \\
\hline Prolonged labour & 381 & 14.7 \\
\hline Cephalopelvic disproportion & 267 & 10.3 \\
\hline 2 or more Caesarean Scars & 228 & 8.8 \\
\hline Malpresentation/Malposition & 178 & 6.8 \\
\hline Fetal Distress & 173 & 6.7 \\
\hline APH & 135 & 5.2 \\
\hline Oligohydramnios & 99 & 3.8 \\
\hline Preeclampsia/Eclampsia & 84 & 3.2 \\
\hline Big baby & 70 & 2.3 \\
\hline Others & 177 & 6.8 \\
\hline
\end{tabular}

\section{B Outcome of Obstructed Labour}

Emergency operations accounted for 97.2\% (2526) of the operations and these included 95.1\% (2473) emergency Caesarean section, $23(0.9 \%)$ repair of uterus, 10 (0.4\%) TAH, 18 (0.7\%) STAH and 2 (0.2\%) exploratory laparotomy for postpartum haemorrhage (Table IV).

Obstructed labour and uterine rupture: Uterine rupture was one of the common complications of obstructed labour and $76.1 \%$ of ruptured uterus occurred in mothers with obstructed labour with the Odds ratio of $7.331 ;(\mathrm{Cl}$ : $3.362-12.675 ; \mathrm{P}$ value 0.000). The percentage of ruptured uterus in mothers with obstructed labour was three times more than in the general population of mothers who had caesarean section. There were 28 primary hysterectomies from obstructed labour or its complications, 21 of these from obstructed labour and others postpartum for mostly for puerperal sepsis. Thus, for every 24 mothers who had obstructed labour, one had a ruptured uterus, but the ratio is 1 in 264 in the general population who underwent Caesarean section which is more than ten times lower. The operations done for ruptured uterus are given in table IV, and the results are comparable with other studies [11, 22]. 


\section{"Prevalence and Outcome of Obstructed Labour at a Tertiary Institution."}

Table IV: Outcome of obstructed labour $(n=2600)$

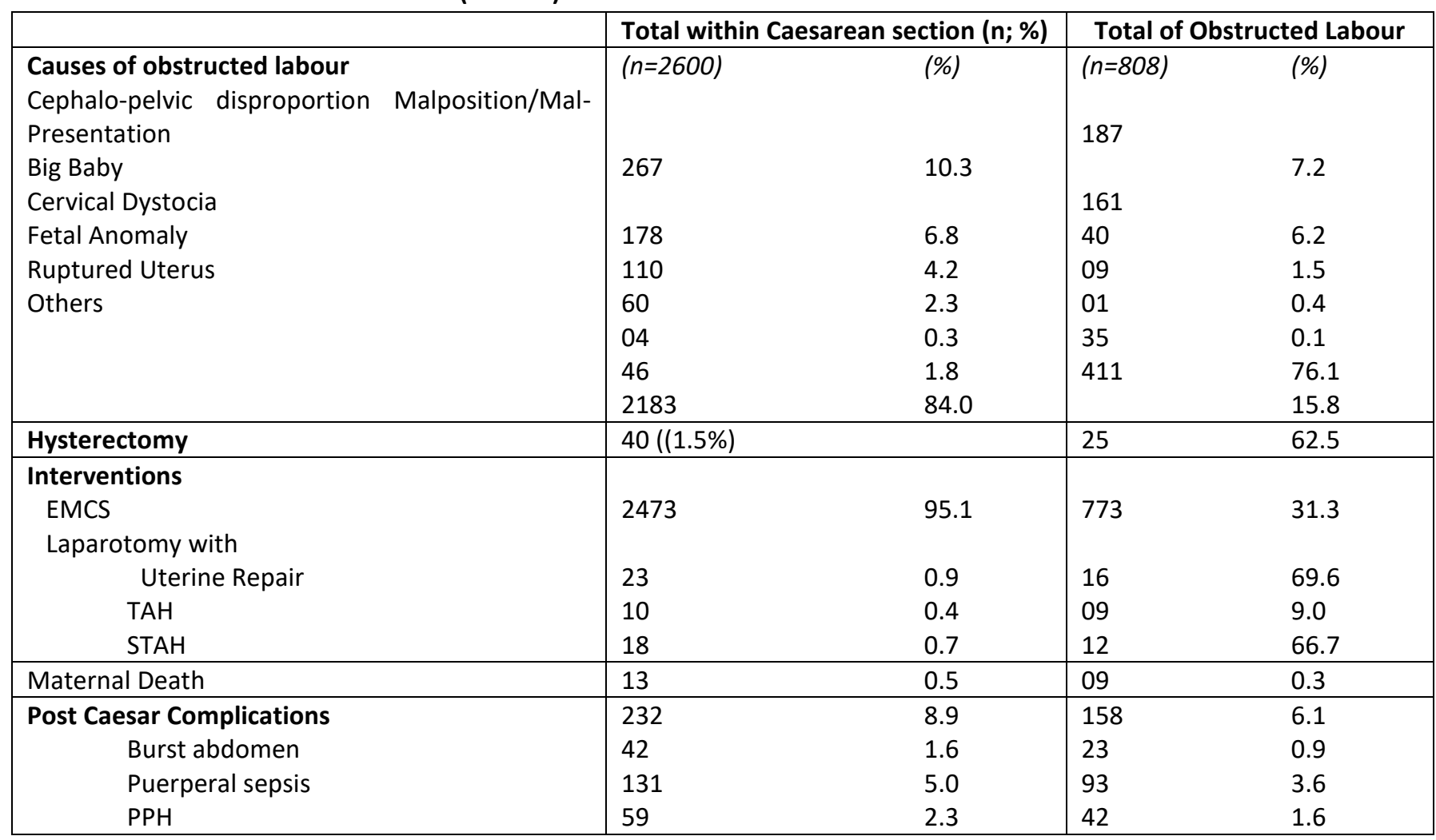

Obstructed labour and Repeat caesarean section scar: Obstructed labour also occurred in mother with previous caesarean section scars to a tune of $6.8 \%$ in mothers who underwent caesarean section and $2.1 \%$ of the total deliveries. Mothers with previous caesarean Section scar were more likely to have obstructed labour than the general population ( $p$ value 0.000$)$, though previous caesarean Section did not increase the risk of obstructed labour ( $\mathrm{Cl}: 0.244$ (0.181-0.327).

Obstructed labour and the interventions: The commonest type of intervention was emergency caesarean section [20] as depicted in table IV (95.1\%) of the mothers with obstructed labour, followed by laparotomy with hysterectomy and laparotomy with uterine repair. For mothers who had obstructed labour, post caesarean section laparotomy was done for 34 (4.3\%) mother who had obstructed labour and puerperal sepsis, 18 mothers with burst abdomen and puerperal sepsis and 6 mothers with PPH. This increased hospital stay, but also loss of fertility potential in these mothers.

Overt Post-operative complications occurred in 232 (8.9\%) mothers who had obstructed labour and these included pyrexia, wound infection, burst abdomen with deep wound sepsis, $\mathrm{PPH}$, and puerperal sepsis. Long term complication like vesical vaginal fistula was recorded in one case while others were transfused either intra or the post-operative period. Many of the mothers had more than one complication in the postnatal period [20].

Obstructed labour and maternal death: There were 13 maternal deaths among the total Caesarean sections and 9 of these followed obstructed labour. Thus, obstructed labour accounted for $69.2 \%$ of the total maternal deaths and mothers with obstructed labour were eight times (OR: 8.904; Cl: 5.044 (1,549-16.428; $\mathrm{p}$ value 0.003) more likely to die than the rest who had caesarean section. Five were due to haemorrhagic shock in the intrapartum period and three due to septicaemia from overwhelming deep wound sepsis and one from postpartum haemorrhage.

Obstructed Labour and Fetal Outcome: Perinatal outcome is shown in table V. There was a 1.2 increased risk of mothers with obstructed labour to deliver a baby with low Apgar score than to deliver dead babies and was not statistically significant implying there were other contributing factors to the low apgar score. Many of the neonates had more than one complications and a high number needed admission to NICU. Complications noted among live births were birth asphyxia, meconium aspiration syndrome, septicaemia, convulsions.

Table V: Obstructed labour and Fetal outcome

\begin{tabular}{|c|ll|ll|}
\hline & \multicolumn{2}{|l|}{ Total Number of births } & \multicolumn{2}{l|}{ Obstructed Labour } \\
\hline Fetal outcome & $(\boldsymbol{n}=\mathbf{2 6 0 0 )}$ & $\mathbf{( \% = 1 0 0 )}$ & $(\boldsymbol{n}=\mathbf{8 0 8 )}$ & $\mathbf{( \% = 3 1 . 1 )}$ \\
Live births & 2375 & 91.3 & 727 & 27.96 \\
\hline
\end{tabular}


"Prevalence and Outcome of Obstructed Labour at a Tertiary Institution."

\begin{tabular}{|l|ll|ll|}
\hline FSB & 146 & 5.6 & 59 & 2.28 \\
MSB & 49 & 1.9 & 12 & 0.46 \\
NND & 30 & 1.2 & 10 & 0.40 \\
\hline APGAR Score & & & & \\
Zero (0) & 198 & 7.6 & 72 & 2.8 \\
Poor (1-4) & 159 & 6.1 & 57 & 2.2 \\
Intermediate & 748 & 28.8 & 267 & 10.3 \\
(5-7) & 1495 & 57.5 & 412 & 15.8 \\
Normal (8-10) & & & & \\
\hline Fetal weight & & & & \\
S999g & 07 & 0.3 & 01 & 0.0 \\
1000-1499g & 21 & 0.8 & 01 & 0.0 \\
1500-2499g & 213 & 8.2 & 24 & 0.9 \\
2500-4000g & 2311 & 88.9 & 774 & 29.8 \\
$\geq 4100$ & 48 & 1.8 & 08 & 0.3 \\
\hline Admission to & 152 & 5.9 & 53 & 2.0 \\
NICU & & & & \\
\hline
\end{tabular}

\section{DISCUSSION}

The prevalence of obstructed labour in this study was $6.6 \%$ among the total deliveries which was comparable with other studies $[13,8,3]$ but higher than the global prevalence of obstructed labour of 3-6\% [20], and other studies done in the country and other areas $[7,11,20,23]$ of the total hospital deliveries. The highest number of obstructed labour was found in the age group 20-29 years which is comparable to other studies [3]. This high trend in prevalence may overestimate the actual incidence in the community since this was a tertiary centre and with a high number of referrals from the lower facility; but also a training centre.

Obstructed labour occurred largely in prime-gravida (23.0\%), those 24 years and below, which is comparable to studies done in South West and Eastern Uganda [7, 23], showing that the main cause of obstruction is primary cephalo-pelvic disproportion, though other studies show a higher prevalence of obstructed labour in multigravida [3]. The large number of multiparous women with obstructed labour could be due to secondary contracted pelvis adult malnutrition, larger size of babies in subsequent pregnancies and decrease abdominal and pelvic muscular tone causing abnormal feto-pelvis axis. This could cause mal-presentation as seen in this study as the second most common cause of obstruction. In the present study, less than half (49.1\%) of those with obstructed labour had the cause of obstruction documented and the commonest causes of obstructed labour were cephalo-pelvic disproportion (23.1\%), mal-presentation/ malposition (6.2\%), macrosomia (5.0\%), dystocia (1.0\%) and fetal abnormality $(0.1 \%)$; similar to other studies $[9,13,1,11,23]$. The fact that most babies were in the normal range of 2500-4000 grams (Table V) signifies a contracted pelvis or malposition/Mal-presentation were the main reasons for the obstructed labour than fetal size which is consistent with a study conducted in Ethiopia [13].

Caesarean section was the only mode of delivery $[13,1]$ performed and laparotomy for complications of obstructed labour. Caesarean section was done for 772 (96.3\%) of the mothers with obstructed labour, followed by laparotomy with hysterectomy in and laparotomy with uterine repair (Table IV). The incidence of ruptured uterus is high and shows late arrivals [3] or poor intrapartum care. Maternal complications reported were also higher. Wound infection was the commonest complication of caesarean section, which may be due to prolonged labour and repeated vaginal examination due to non-use of the Partograph for timed examinations. Other common complications included pyrexia, genital sepsis, PPH, uterine sub-involution, and fertility loss due to hysterectomy; which was then accompanied by psychological stress.

Various studies have reported obstructed labour to be a major cause of maternal and perinatal mortality. In this study, maternal and perinatal mortality and morbidity was high. Following obstructed labour there were a high number of maternal death compared to non-obstructed caesarean section. Maternal mortality in the study group was $9 / 808$ in obstructed labour (13/2600 Caesarean section), due to PPH and sepsis mainly [3].

Regarding the perinatal outcome, 727 (91.4\%) were live births, higher than in other studies [23] with a perinatal mortality of 8.6\% with 58 (5.9) still birth, 9 (0.9\%) early neonatal deaths, and 12 (1.9\%) macerated birth. Complications noted among live births were birth asphyxia, meconium aspiration syndrome, septicaemia, neonatal Jaundice, which was comparable to other studies [9, 23]. 


\section{"Prevalence and Outcome of Obstructed Labour at a Tertiary Institution."}

This study also showed obstructed labour to be one of the major causes of poor perinatal outcome with low first minute Apgar score, high admission to NICU, prolonged hospital stay, and perinatal death.

\section{Limitation of the study}

The retrospective nature of the study and lack of some data due to incomplete or inadequate recording of certain variable.

There was no assessment of health care providers' knowledge and attitude on why there was low usage of the partograph even when it is the admission tool to labour suite; there was an increased number of institutional cases of obstructed labour due to lack of adequate monitoring.

The causes of obstruction were not documented in majority of the deliveries, making it difficult to coin appropriate interventions.

\section{CONCLUSION}

Obstructed labour is totally preventable but unfortunately it is a major cause of maternal and perinatal morbidity and mortality in resource limited environment; and the prevalence is still high. Maternal death, post-operative pyrexia and sepsis, loss of fertility and prolonged hospital stay were some of the most common complications faced by the mothers with obstructed labour. Poor referral system or late referral, non-functional comprehensive obstetric health facilities, inadequate intrapartum labour care with non-use of the partograph during labour produced many cases of obstructed labour. Good early childhood nutrition, education of primary health care providers on dangers of obstructed labour, use of the partograph during active labour, functional emergency obstetric units and early referral with a functioning referral system are suggested to reduce the prevalence of obstructed labour. This study revealed that there was a high prevalence of obstructed labour but the cause of obstruction was poorly documented that would guide in formulating interventions to prevent obstruction. Early recognition and safe abdominal delivery can reduce the maternal and perinatal morbidity and mortality.

\section{ACKNOWLEDGEMENT}

All the staffs of the Department of Obstetrics \& Gynaecology, for their continuous guidance and motivation to this work.

\section{REFERENCES}

1) Gupta. R and Porwal. S.K, "Obstructed labour: Incidence, causes and outcome," International Journal of Biological and Medical Research, vol. 3, no. 3, pp. 2185-2188, 2012.

2) Gessessew. A and Menengiste. M, "Obstructed labour in Adigrat Zonal Hospital, Tigray region, Ethiopia," Health Dev, vol. 17, no. 3, pp. 175-180, 2003.

3) Ranjana. A.S, "Incidence, causes and feto-maternal outcomes of obstructed in a tertiary health care centre," International Journal of Reproduction, Contraception, Obstetrics and Gynecology labour in a tertiary health care centre., vol. 6, no. 7, pp. 2817-2821, 2017.

4) Prual. A, Bouvier-Colle. M, Bernis. L.d. and Bréart. G, "Severe maternal morbidity from direct obstetric causes in West Africa: incidence and case fatality rates," Bull World Health Organ, vol. 78, no. 5, pp. 593-602, 2000.

5) Udoma. J.E, Asuquo. D.E, Mildred. E.J and Atim. I.E, "The role of institutional factors in Maternal Mortality from obstructed labour," Global Journal of Medical Sciences, vol. 2, no. 1, pp. 13-17, 2003.

6) Orach. C. G, "Maternal mortality estimated using the Sisterhooh method in Gulu District, Uganda," Tropical Doctor, vol. 30, no. 2, pp. 72-74, 2000.

7) Kabakyenga. J, Per-Olof. O, Eleanor, Turyakira, Peter. K. M, Karen, and Odberg. P, "Individual and health facility factors and the risk for obstructed labour and its adverse outcomes in South-Western Uganda," BMC Pregenancy and Childbirth, vol. 11, no. 73, 2011.

8) Ritu. G and Sanjay. K.P, "Obstructed Labour: Incidence, causes and outcome," International Journal of Biological \& Medical Research, vol. 3, no. 3, pp. 2185-2188, 2012.

9) Asnakech. T.G,Tilaye. W.A, Fikiru. A.G, Godana and Guto. J, "Magnitude of Obstructed Labour and Associated Risk Factors among Mothers Come for Delivery Service in Adama Hospital Medical College, Oromia Regional State, Central Ethiopia," Ethiopia. Journal of Gynecology and Obstetrics, vol. 4, no. 3, pp. 12-16, 2016.

10) Henok. A and Asefa. A, "Prevalence of Obstructed Labour among Mothers Delivered in Mizan-Aman General Hospital, South West Ethiopia: A Retrospective Study," Journal of Women Health Care, vol. 250, p. 4, 2015. 


\section{"Prevalence and Outcome of Obstructed Labour at a Tertiary Institution."}

11) Sharma. P, Kalpana. K, Vaibhav. K and Seth. S, "Obstructed Labour: A Preventable Tragedy but still a long way to go in Developing Countries," International Journal of Health Science and Research, vol. 5, no. 9, pp. 99-104, 2015.

12) Carmen.D and Carla.A, "Evidence and Information for Policy (EIP),World Health Organization, Geneva," Global burden of obstructed labourin the year 2000, 2000.

13) Henok. A and Asefa. A, "Prevalence of Obstructed Labour among Mothers Delivered in Mizan-Aman General Hospital, South West Ethiopia: A Retrospective Study.," Journal of Women's Health Care, vol. 4, no. 250, pp. 4-5, 2015.

14) Shimelis. F, Hailemarian. S, and Fessahaye. A, "Incidence, causes and outcome of obstructed labour in Jima University specialized hospital," Ethiopian Journal of Health Science, vol. 20, no. 3, pp. 145-151, 2010.

15) Shaikh, S. Shaikh, A. Shaikh. SAH, and Isran. B, "Frequency of Obstructed Labour in Teenage Pregnancy," NJOG, vol. 7, no. 3, pp. 37-40, 2012.

16) Ahmed. E, EL. Nwobondo and Y "Obstructed labour: A public health problem in Sokoto, Nigeria," Sahel Medical Journal, vol. 14, no. 3, pp. 140-142, 2011.

17) WHO, "Appropriate technology for bbirth," Lancet, vol. 2, no. 8452, pp. 436-437, 1985.

18) Mi. J and Liu. F, "Rate of Caesarean section is alarming in China," Lancet, vol. 383, no. 9927, pp. 1463-4, 2014.

19) Priya. S, Kalpana. K, Vaibhav. K and Shikha.S, "Obstructed Labour: A Preventable Tragedy but Still a Long Way to Go In Developing Countries," International Journal of Health Sciences \& Research, vol. 5, no. 9, pp. 99-104, 2015.

20) Kongnyuy. E, Mava. G and Broek. V, "Establishing standards for obstructed labour in low-income country Rural and Remote Health," Online, vol. 1022, no. 8, pp. 1-10, 2008.

21) Kadowa. I, "Ruptured uterus in rural Uganda: prevalence, predisposing factors and outcomes," Singapore Med Journal, vol. 51, no. 1, pp. 355-38, 2010.

22) Sabyasachi. M, Arunima. C, Gourisankar.K and Santra. D, "Fetomaternal outcome in obstructed labour in aperipheral tertiary care hospital," Medical Journal of Dr. D.Y. Patil University, vol. 6, no. 2, 2013.

23) Milton. W.M, Grace. N, Justus. K. B, Andrew. W, Victoria. N, Felix. W, Daniel. S, James. K.T and Julius. N.W, "Risk factors for obstructed labour in Eastern Uganda: A case control study," PLOS ONE, vol. 15, no. 2, 2020.

24) Omar. K, Hasim. S, Muhammad NA. J.A.H.S and Siraj. H, "Adolescent pregnancy outcome and risk fators in Malaysia," International Journal of Gynecology and Obstetrics, vol. 111, no. 3, pp. 220-223, 2010.

25) Naz.S, Paeveen. R, Bhatti. A, Baloch. R and Hanif. M, "Tennage pregnancy (Are tennager a risk group?)," Medical Channels of Pakistan Gynecology and Obsterics, pp. 140-143, 2010. 